\title{
Tests of mechanical properties of semicrystalline and amorphous polymeric materials produced by 3D printing
}

\author{
Piotr Sikora ${ }^{1, *}$, Adam Gnatowski ${ }^{1}$, and Rafał Gołębski ${ }^{1}$ \\ ${ }^{1}$ Politechnika Częstochowska, Wydział Inżynierii Mechanicznej i Informatyki, 42-200 Częstochowa, \\ Poland
}

\begin{abstract}
The article presents the results of tests of physical properties of samples from semi-crystalline and amorphous polymeric materials produced using 3D printing. Samples were produced using 3D printing technology on the SIGNAL -ATMAT printer. The following polymeric materials were used to make the samples: TPU - thermoplastic polyurethane elastomer, ABS - acrylonitrile-butadiene-styrene copolymer, Laywood, PET - ethylene terephthalate, PLA - poly (lactic acid). The materials were tested for their mechanical properties. The hardness was determined by the Shore method and the ball-pressing method. The tensile strength also was determined. The research samples were subjected to visual analysis on a Keyence microscope to analyze the breakthrough site.
\end{abstract}

Keywords: tensile strength, hardness, polymer materials, 3D print

\section{Introduction}

Elements of machines and devices made by 3D printing are used in various industry sectors, more often appearing in everyday use. Creating an element is not expensive, comparing to the cost of making injection molds, the ease of designing and making a given shape, even a very complicated one [1,2]. Users of modern 3D printers can be satisfied by the latitude of made parts, thanks to ever more accurate application of subsequent layers of filament, they are able to get even narrow dimensional tolerances, as well as shape and position tolerances. Among the tested materials used for 3D printing, the Laywood woodlike material has been mentioned, which has a characteristic dark brown color and emits resembling wood smell during the $3 \mathrm{D}$ printing process. It gives the elements the appearance of a fibreboard and behaves like wood thus it can be abraded or painting. This material is used in producing architectural models, decorations and furniture components [3]. Amorphous acrylonitrile-butadiene-styrene used in 3D printing technology is a material characterized by high strength, it works well on printing moving parts, has a high temperature resistance and an increased level of flexibility [4]. During the printing material is emitting intense vapors that can pose a risk to people and animals. Such fumes mean that

\footnotetext{
* Corresponding author: psikora@wimii.pcz.pl

Reviewers: Supplemented by Organizing Committee of MMS 2017
} 
the printing must take place in embedded printers and located in well ventilated rooms. PLA is another tested material. It is fully biodegradable. It is obtained from renewable natural resources [5]. This is one of the most frequently used 3D printing materials. This material is characterized by a slight shrinkage of the material, which makes it perfect for demonstration prints, such as: mock-ups or prototype elements. PLA is not suitable for printing moving parts due to its low flexibility and low temperature resistance [6]. The most important thing when making items with the above-mentioned method is choosing the right material. Incorrect selection of material and process parameters to the type of the element being made may cause for example: early wear of the element, difficulties in obtaining adequate model accuracy, incomplete filling [7]. Another difficulty occurring in the $3 \mathrm{D}$ printing process is the selection of appropriate process parameters such as: filament diameter, printing temperature or table temperature, incorrect selection of these factors may result in: clogging printer nozzles, larger than planned material contractions, incomplete plasticization when applying subsequent layers, which causes delamination of the element and the occurrence of non-uniformity of the filling of the model causing its strength to decrease [8]. The aim of the work is to analyze changes in mechanical properties of materials used to produce elements using $3 \mathrm{D}$ printing. The following materials were used for the tests: ABS, Laywood, PLA, PET, TPU [9].

\section{Research methodology}

DEVIL DESIGN filaments with a thickness of $1.75 \mathrm{~mm}$ were used in the research. Filaments were made of the following polymer materials: Laywood, ABS, PLA, PET, TPU. Samples were produced using 3D printing technology on an ATMAT SIGNAL printer, with the possibility of mounting nozzles with a passage from $0.1 \mathrm{~mm}$ to $1.0 \mathrm{~mm}$. The printer's nozzle allows heating to $270^{\circ} \mathrm{C}$, the table was heated to $110^{\circ} \mathrm{C}$. The accuracy of filament printing is $0.1 \mathrm{~mm}$ for speeds from 0.1 to $1 \mathrm{~cm}^{3} / \mathrm{min}$. 3D printing was done using a $0.8 \mathrm{~mm}$ nozzle and DIMAFIX adhesive was applied to the table. The most favorable properties were obtained because of the printing parameters set (Table 1).

Table 1. Parameters of printing samples

\begin{tabular}{|c|c|c|c|c|c|}
\hline Sample & LAYWOOD & ABS & PLA & PET & TPU \\
\hline $\begin{array}{c}\text { Nozzle } \\
\text { temp. }\end{array}$ & $220^{\circ} \mathrm{C}$ & $230{ }^{\circ} \mathrm{C}$ & $230{ }^{\circ} \mathrm{C}$ & $242{ }^{\circ} \mathrm{C}$ & $250^{\circ} \mathrm{C}$ \\
\hline $\begin{array}{c}\text { Table } \\
\text { temp. }\end{array}$ & $55^{\circ} \mathrm{C}$ & $100{ }^{\circ} \mathrm{C}$ & $55^{\circ} \mathrm{C}$ & $60^{\circ} \mathrm{C}$ & $60{ }^{\circ} \mathrm{C}$ \\
\hline $\begin{array}{c}\text { Printing } \\
\text { speed }\end{array}$ & $60 \mathrm{~mm} / \mathrm{s}$ & $60 \mathrm{~mm} / \mathrm{s}$ & $60 \mathrm{~mm} / \mathrm{s}$ & $50 \mathrm{~mm} / \mathrm{s}$ & $25 \mathrm{~mm} / \mathrm{s}$ \\
\hline $\begin{array}{c}\text { Filament } \\
\text { applicati } \\
\text { on speed }\end{array}$ & $\begin{array}{c}\text { Compliant } \\
\text { with the } \\
\text { recommendati } \\
\text { ons }\end{array}$ & $\begin{array}{c}\text { Compliant } \\
\text { with the } \\
\text { recommendacturer's } \\
\text { ons }\end{array}$ & $\begin{array}{c}\text { Compliant } \\
\text { with the } \\
\text { manufacturer's } \\
\text { recommendati } \\
\text { ons }\end{array}$ & $\begin{array}{c}\text { Compliant } \\
\text { with the } \\
\text { manufacturer's } \\
\text { recommendati } \\
\text { ons }\end{array}$ & $\begin{array}{c}\text { Compliant } \\
\text { with the } \\
\text { manufacturer's } \\
\text { recommendati } \\
\text { ons }\end{array}$ \\
\hline
\end{tabular}




\begin{tabular}{|c|c|c|c|c|c|}
\hline $\begin{array}{c}\text { Layer } \\
\text { height }\end{array}$ & $0.21 \mathrm{~mm}$ & $0.21 \mathrm{~mm}$ & $0.21 \mathrm{~mm}$ & $0.21 \mathrm{~mm}$ & $0.21 \mathrm{~mm}$ \\
\hline $\begin{array}{c}\text { Print } \\
\text { cooling }\end{array}$ & YES & YES & YES & YES & YES \\
\hline Fulfilling & $96 \%$ & $96 \%$ & $96 \%$ & $96 \%$ & $96 \%$ \\
\hline
\end{tabular}

Hardness tests of samples were carried out using two methods: Shore, according to the standard PN-EN ISO 868:2005 and the ball-pressing method according to PN-EN ISO 2039-1:20004. The edges of the samples were not tested because they were made with a different stitch than the center of the element. The stitch around the edge of the sample was $100 \%$ filled, while the entire sample was $96 \%$ filled. Table 2 presents: the type of scale used for Shore hardness, for the ball-pressing method and the value of force which was acted to the ball. Strength was measured using a static tensile test. These tests were based on the PN-EN ISO 527-2:2012 standard. The samples were picked at the ZWICK100 electromechanical machine with a measuring range of $0-100 \mathrm{kN}$. After strength testing, sample breakthroughs were analyzed on a Keyence VHX-6000 microscope. The research was carried out at a magnification of 50 times, which allowed to obtain a 3D image, given by applying images with variable focus in the vertical axis.

Table 2. Scale for Shore hardness, and force for ball indentation method

\begin{tabular}{|c|c|c|}
\hline \multirow{2}{*}{ Material } & Shore & Ball indentation method \\
\hline LAYWOOD & D & $132 \mathrm{~N}$ \\
\hline PLA & D & $358 \mathrm{~N}$ \\
\hline TPU & D & $49 \mathrm{~N}$ \\
\hline ABS & D & $132 \mathrm{~N}$ \\
\hline PET & D & $358 \mathrm{~N}$ \\
\hline
\end{tabular}

\section{Test results}

Figs. 1 to 2 shows the stretching curves of the tested materials, whereas in Tab. 3, the results of the tested materials obtained during the uniaxial stretching test are presented. 


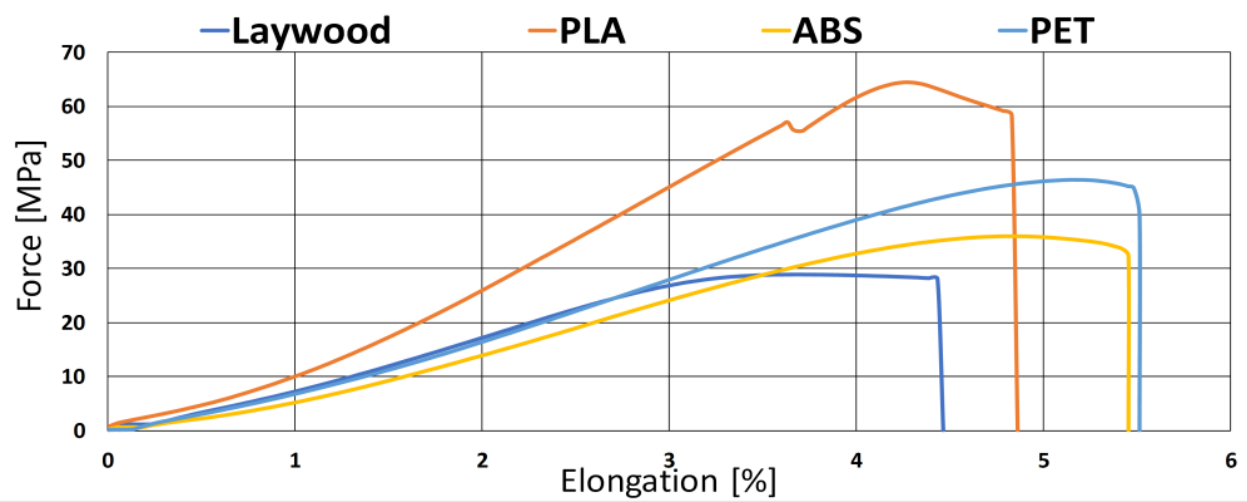

Fig. 1. Relations between elongation and force for LAYWOOD, PLA, ABS, PET

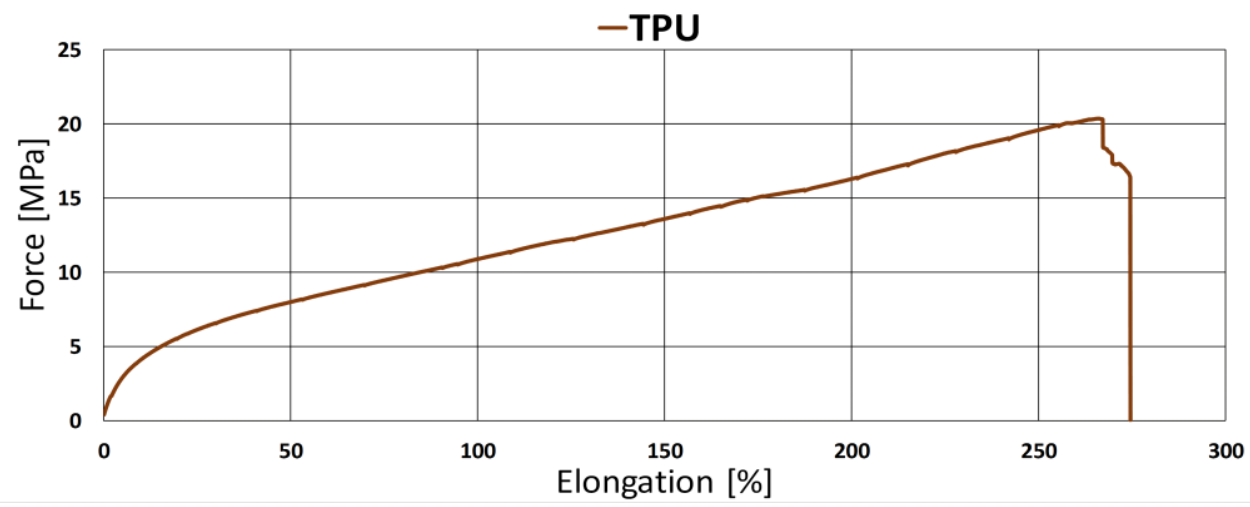

Fig. 2. Relations between elongation and force for TPU

Table 3. Results of tensile strength testing

\begin{tabular}{|c|c|c|}
\hline Material & Fmax $[\mathrm{N}]$ & $\mathrm{Rm}[\mathrm{MPa}]$ \\
\hline LAYWOOD & 1158 & 29 \\
\hline PLA & 2498 & 62 \\
\hline TPU & 623 & 36 \\
\hline ABS & 1441 & 46 \\
\hline PET & 1857 & 36 \\
\hline
\end{tabular}

On the basis of the results presented in the graphs and in the test results table, PLA 2498 $\mathrm{N}$ is characterized by the highest breaking force, while the lowest force required to break the sample is characterized by the TPU $623 \mathrm{~N}$ elastomer. The TPU breakage plot is peculiar, because it shows three rapid decreases value of force, which in this case indicates 
probably the cracking of single filament filaments before complete breakage. On the Laywood chart, on the other hand, the visible shape of the curve probably indicates that before the break-up, the particles of wood dust separated from each other from the binder that is TPU.

The results of hardness testing by ball injection are shown in Fig. 6.

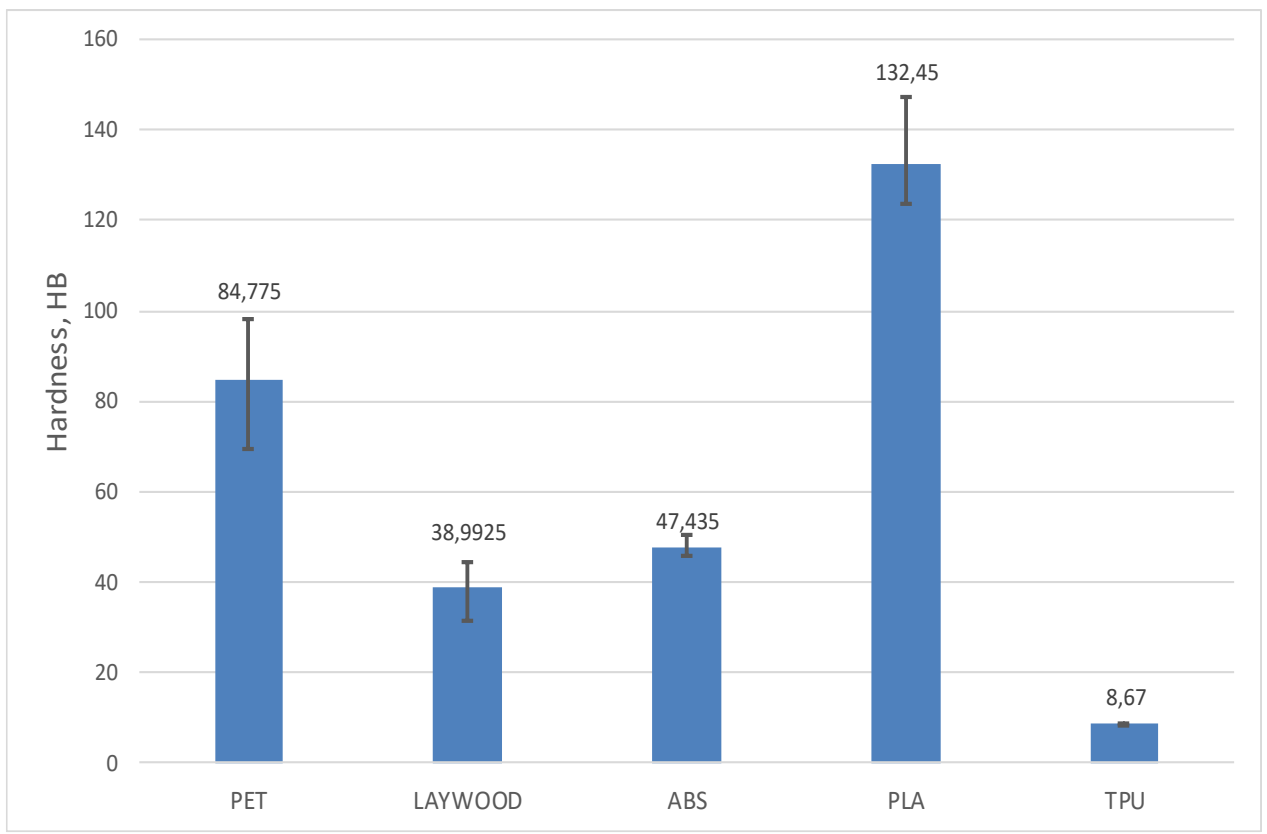

Fig. 3. Ball indentation method hardness

The highest hardness determined by means of this method is characterized by PLA, amounting to $132.45 \mathrm{MPa}$, the lowest hardness in this test is characterized by TPU elastomer 8.67 MPa. The biggest difference between the minimum and maximum result is PET. It is up to $29.12 \%$. Shore hardness test results are presented in Fig. 4. 


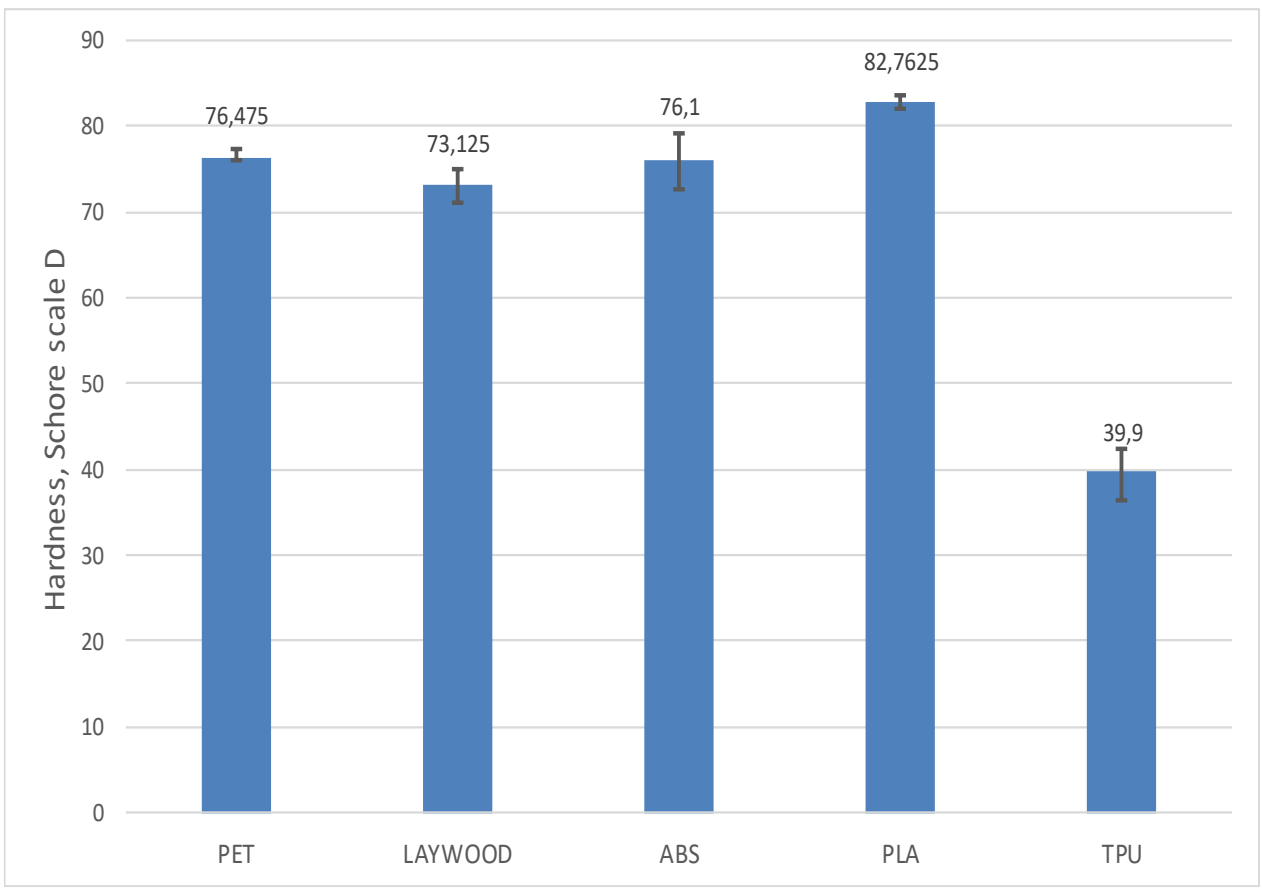

Fig. 4. Shore'a hardness

In this case, the highest hardness is characterized by a PLA of $82.76^{\circ} \mathrm{Sh}$, the lowest hardness was obtained by the TPU elastomer of $39.9^{\circ} \mathrm{Sh}$. The largest spread between the maximum and minimum result occurred at TPU and amounted to $14.18 \%$. In this case, it can be seen that the more accurate test of hardness for 3D prints is the Shore test, the spread of results is presented in Tab. 4.

Table 4. \% Difference in max. and min. hardness

\begin{tabular}{|c|c|c|}
\hline \multirow{2}{*}{ Material } & Shore & Ball indentation method \\
\hline PET & $1.81 \%$ & $29.12 \%$ \\
\hline LAYWOOD & $5.33 \%$ & $28.89 \%$ \\
\hline ABS & $8.08 \%$ & $9.67 \%$ \\
\hline PLA & $1.79 \%$ & $16.10 \%$ \\
\hline TPU & $14.18 \%$ & $1.60 \%$ \\
\hline
\end{tabular}

Figures 8-12 are presenting actual 3D models of breakthroughs caused by cracking the samples. 


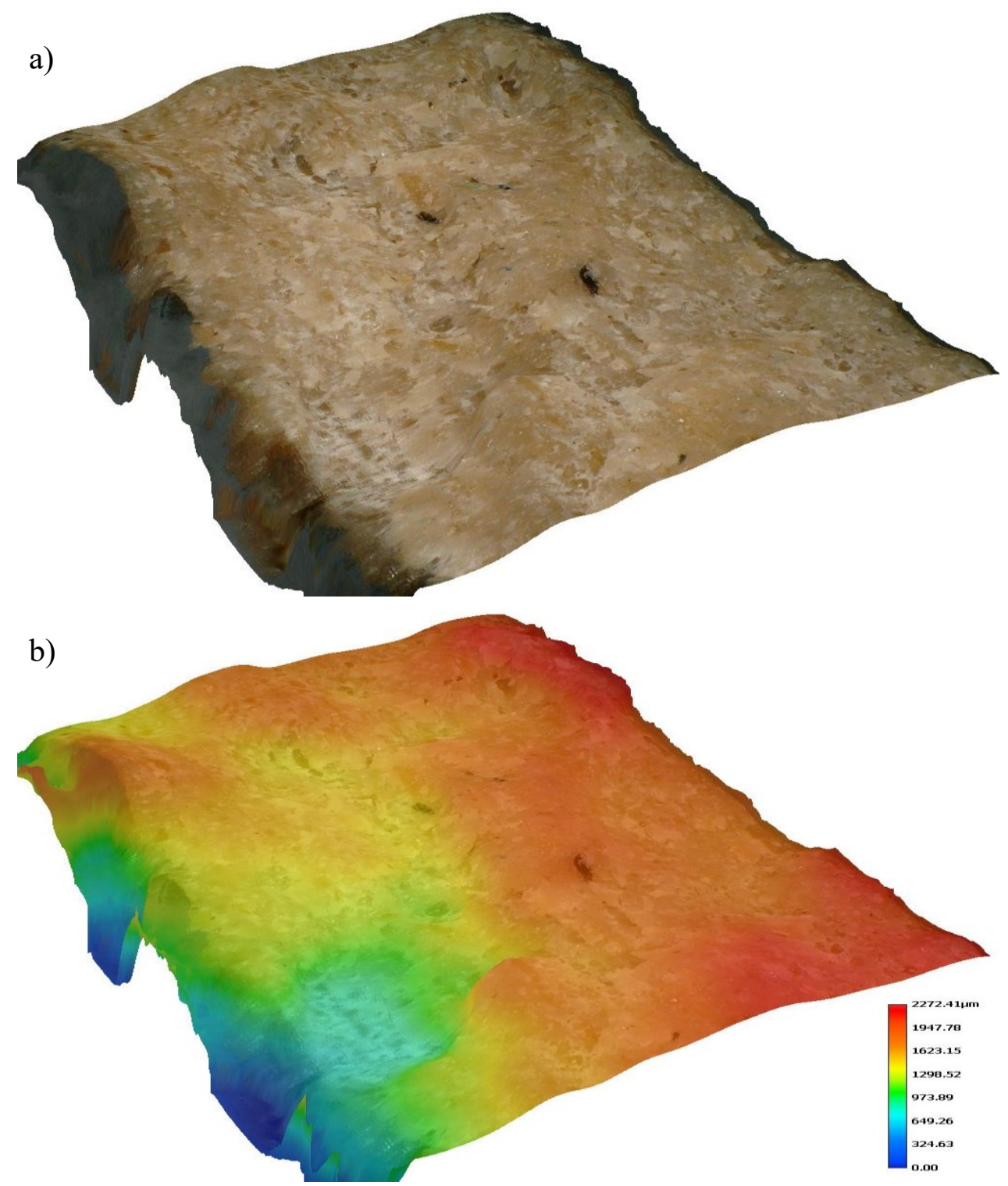

Fig. 5. 3D breakthrough LAYWOOD: a) normal colour b) height colour gradient 


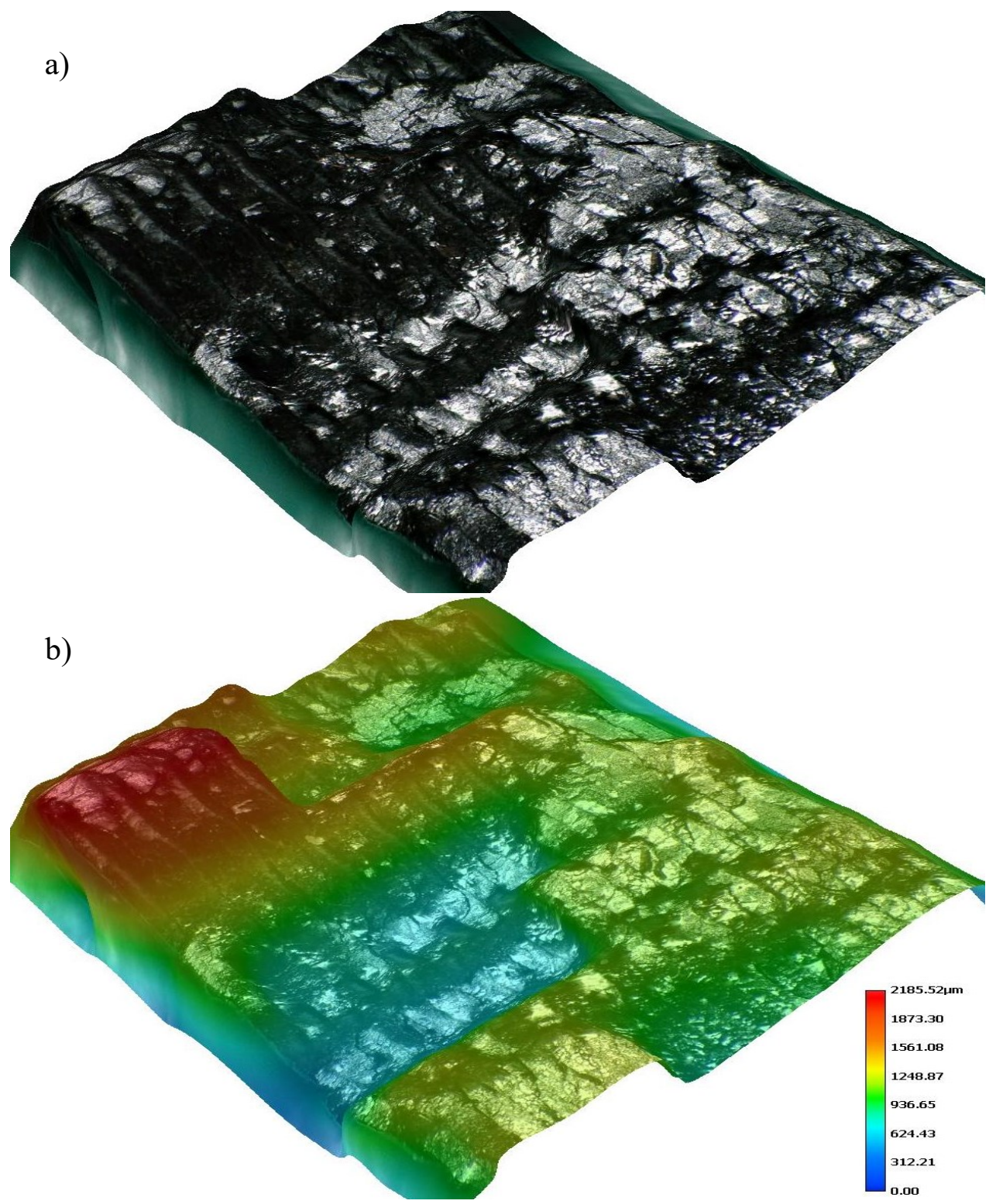

Fig. 6. 3D breakthrough PLA: a) normal colour b) height colour gradient 


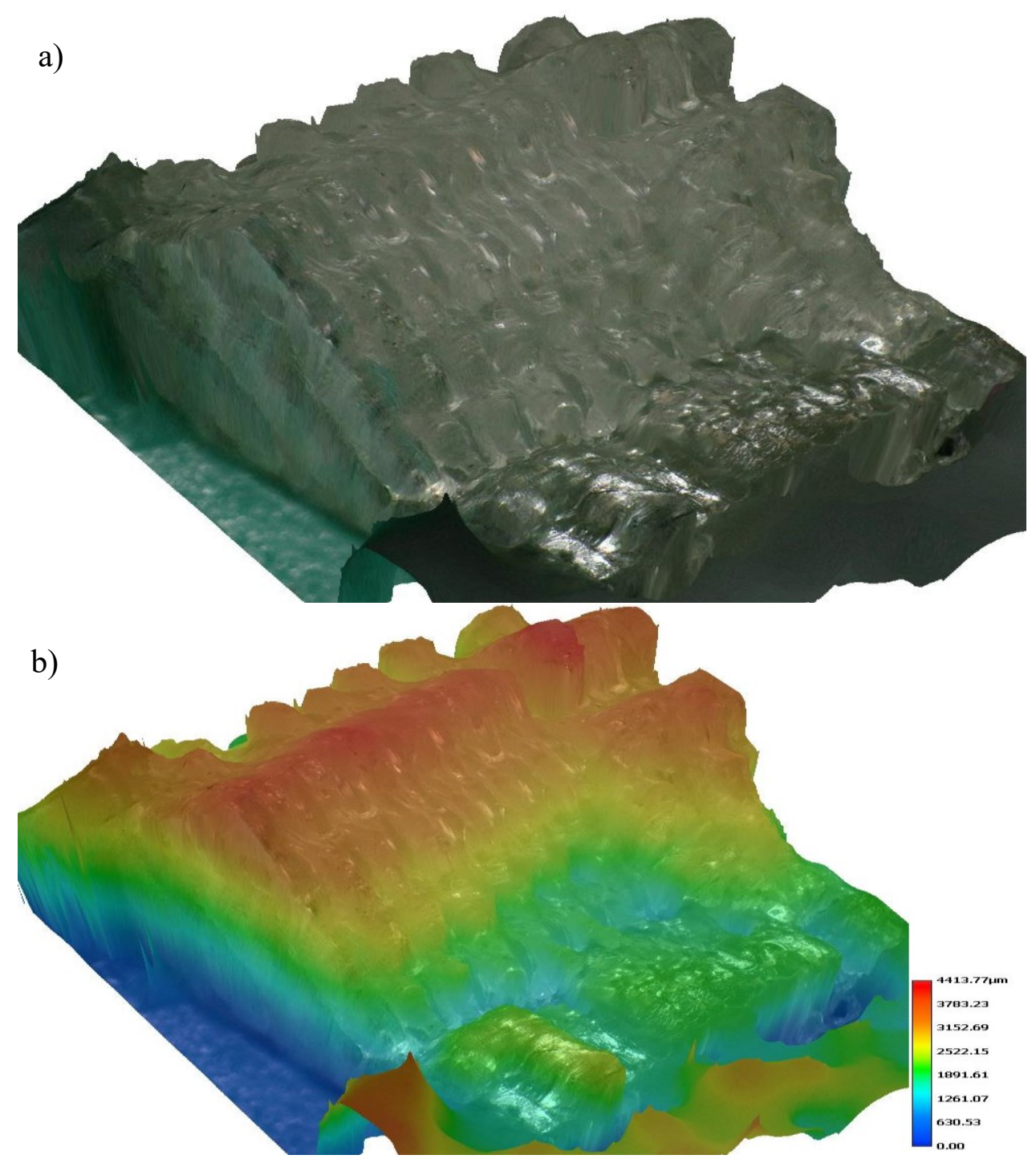

Fig. 7. 3D breakthrough TPU: a) normal colour b) height colour gradient 


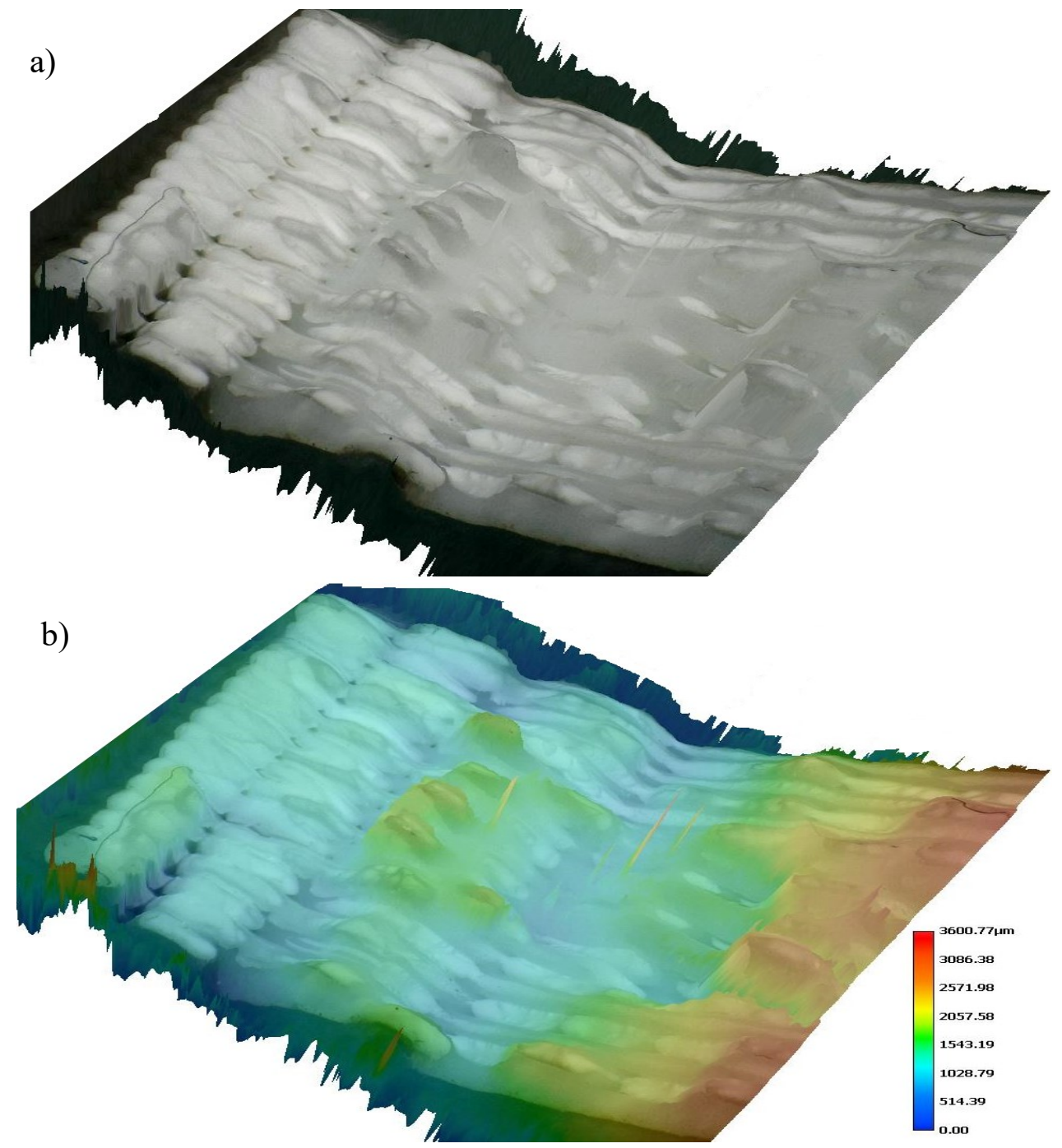

Fig. 8. 3D breakthrough ABS: a) normal colour b) height colour gradient 


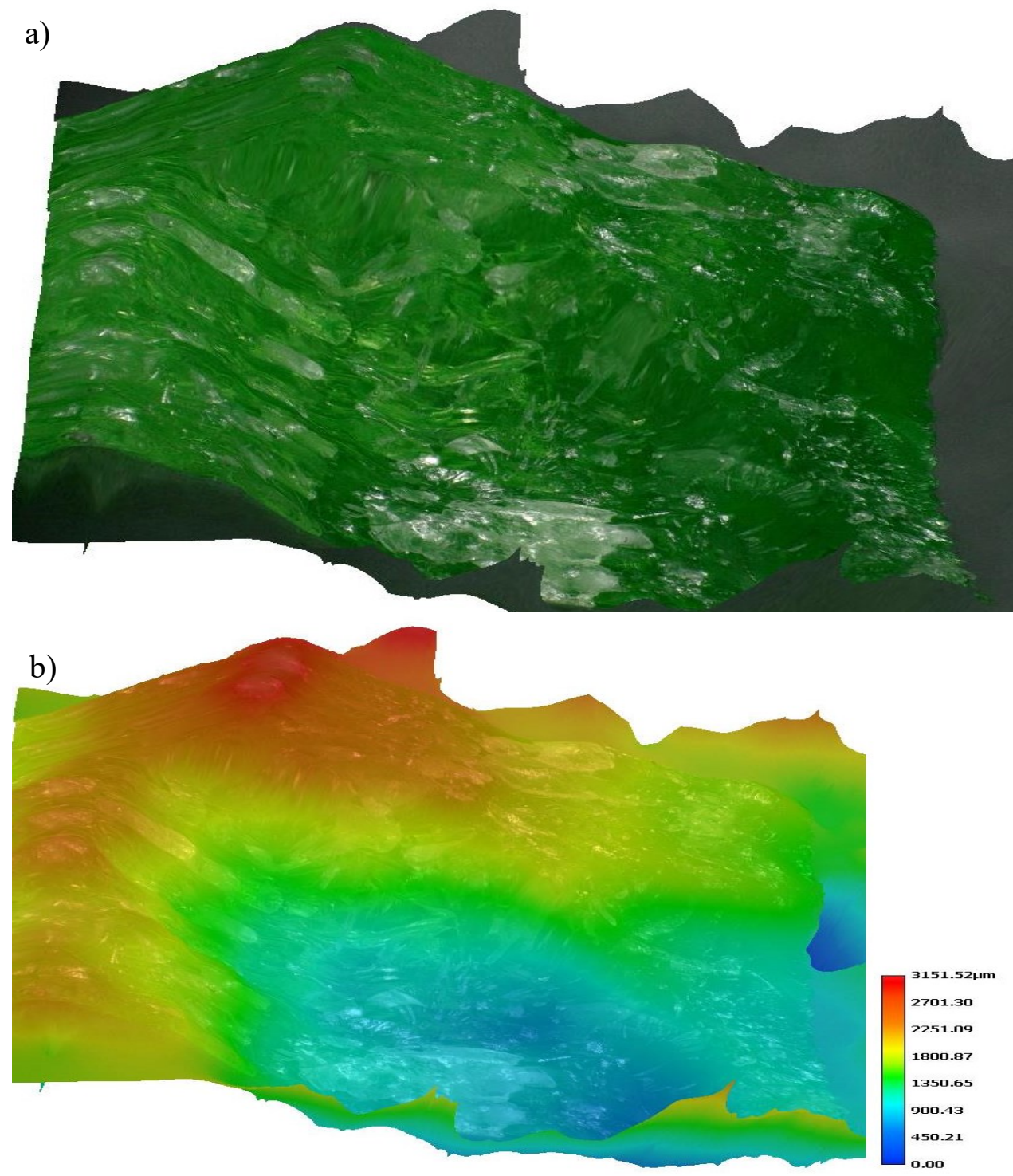

Fig. 9. 3D breakthrough PET a) normal colour b) height colour gradient

On the basis of the breakthroughs, it can be seen that only LAYWOOD was not interrupted along the overlapping layers of filament. You can also see that the LAYWOOD breakthrough is the least frayed and the most flat. Among the polymers in which the cracks are compatible with the layers laid down successively, the largest delamination can be seen in the TPU. The PLA rupture is characterized by delamination with the smallest height difference and the most compact layer form.

\section{Conclusions}

On the basis of hardness tests, it can be concluded that the most accurate results in the case of the tested materials can be obtained with the Shore method because in the pressing-ball 
method there are radial forces coming from the center of the ball, which causes tearing of the polymer layers. In the Shore method the pressure force is axial which does not cause tearing of the printed polymer layers. It gives more accurate result and the differences between the results on one sample have greater clumping.

Breakthrough research in the uniaxial stretching show that the samples break along subsequent filament paths, which indicates a low integration degree of successive layers. The most combined material is LAYWOOD because it was not delaminated during stretching, and its breakthrough was characterized by the smallest difference between the highest and the lowest layer.

There is also a visible relation between the hardness of the material and its tensile strength because as the value of hardness decreases, the distance to achieve the critical value of the axial load is increased until complete cracking. It is visible in PLA because it breaks off immediately after reaching the maximum axial load, while TPU breaks slowly as indicated by peaks on the graph.

\section{References}

1. https://www.3ders.org/3d-printing/3d-printing-history.html

2. M. Košík, J. Bílik, D. Rolando Delgado Sobrino, M. Košík et al., Reduction of Injection Moulded Plastic Part Warpage Using Advanced Gas Assisted Injection Moulding. Materials Science Forum, Vol. 862, 200-209 (2016)

3. http://ijpaliga.pl/rodzaje-druku

4. H. Lipson,. Fabricated, The new world of $3 D$ printing. Indianapolis, Indiana. ISBN 9781118350638. OCLC 806199735.4

5. A. Kaziunas, Make, 3D Printing: The Essential Guide to 3D Printers, Maker Media, 2013

6. http://web.mit.edu/tdp/www/whatis3dp.html

7. A. Thomas, The 3D Trainwreck: How 3D Printing Will Shake Up Manufacturing. Analog. 128 (11), 50-63 (2008)

8. B. Stephens, P. Azimi, Z. El Orch, T. Ramos, Ultrafine particle emissions from desktop 3D printers. Atmospheric Environment 79, 334-339 (2013)

9. J. T. Tran The Law and $3 D$ Printing. John Marshall Journal of Information Technology and Privacy Law 31, 505-20 (2015) 